\title{
“TUDO O QUE VOCÊ DISSER VIRA PESQUISA": Trilhando caminhos teórico-metodológicos na pesquisa com internautas
}

\author{
Dilton Ribeiro do Couto Junior \\ Maria Luiza Magalhães Bastos Oswald ${ }^{(*)}$
}

\begin{abstract}
A palavra não é um objeto, mas um meio constantemente ativo, constantemente mutável de comunicação dialógica. Ela nunca basta a uma consciência, a uma voz. Sua vida está na passagem de boca em boca, de um contexto para outro, de um grupo social para outro, de uma geração para outra. Nesse processo ela não perde o seu caminho nem pode libertar-se até o fim do poder daqueles contextos concretos que integrou. (BAKHTIN, 2008, p. 232).
\end{abstract}

O interesse da pesquisa em ciências humanas não é pela língua como objeto específico da linguística, mas pela comunicação dialógica que, segundo o filósofo russo Mikhail Bakhtin, “constitui o verdadeiro campo da vida da linguagem" (2008, p. 209, grifo do autor). Vida é o que não falta na pesquisa em educação preocupada em conhecer o que dizem de si os sujeitos expressivos e falantes. Esses sujeitos contam e recontam histórias, ao passo que convidam o pesquisador a participar do encontro com tantos outros, impulsionados pelo desejo de aprender e ensinar. Na perspectiva bakhtiniana, o encontro com o outro privilegia as dimensões dialógica, alteritária e polifônica do discurso.

Para Bakhtin (2011), a linguagem é o convite para o encontro com o outro. Nas palavras dele, "ser significa ser para o outro e, através dele, para si. O homem não tem um território interior soberano, está todo e sempre na fronteira, olhando para dentro de si ele olha o outro nos olhos ou com os olhos do outro" (p. 341, grifos do autor). Ao mesmo tempo em que constitui-se como um processo permanente de negociação, a linguagem é o convite para que os sujeitos criem formas de interagir cotidianamente. Os sentidos produzidos na relação entre os sujeitos revela que há formas distintas de perceber e interpretar os acontecimentos da vida.

Fruto de pesquisa em andamento de doutorado, o objetivo do texto é promover algumas reflexões teórico-metodológicas sobre os caminhos que vêm sendo trilhados na pesquisa com internautas. No diálogo com os jovens pesquisados, adotou-se como perspectiva a abordagem

\footnotetext{
${ }^{(*)}$ Dilton Ribeiro C. Junior. Doutorando do Programa de Pós-graduação em Educação da Universidade do Estado do Rio de Janeiro (ProPEd/UERJ). Membro do Grupo de Pesquisa Infância, Juventude, Educação e Cultura (IJEC). Bolsista Capes. UERJ. E-mail: junnior_2003@yahoo.com.br.

Maria Luiza M. B. Oswald. Professora da Faculdade de Educação e do Programa de Pós-graduação em Educação da Universidade do Estado do Rio (ProPEd/UERJ). Líder do Grupo de Pesquisa Infância, Juventude, Educação e Cultura (IJEC).E-mail: moswalduerj@yahoo.com.br.
} 
dialógica de Mikhail Bakhtin, segundo a qual rompe-se com a ideia da superioridade do pesquisador sobre os pesquisados, entendendo-se que todos somos coautores na produção do conhecimento. Essa orientação teórico-metodológica permitiu que os jovens sujeitos fossem compreendidos como parceiros da tarefa de conhecer o que ainda é desconhecido, em um processo de investigação que constrói-se gradualmente com o outro.

A partir das questões apresentadas no texto, não buscamos respostas conclusivas, pois as dinâmicas de interação social na internet não admitem um manual de como fazer. E por quê entrelaçar as ideias de Mikhail Bakhtin ao texto? Afinal, quais seriam as contribuições do filósofo e pensador que nasceu no final do século XX e faleceu muito antes da popularização da internet e do computador pessoal, para pensar questões de pesquisa na cibercultura? Geraldi (2013) apresenta um ponto de vista interessante ao mostrar que, mesmo não tendo escrito nada especificamente sobre educação, Bakhtin nos ajuda a entender sobre a formação dos homens. Geraldi acrescenta ainda a ideia de que "é porque escreveu o que escreveu que podemos dizer que Bakhtin disse tudo o que disse também aos educadores, que muito podem dizer a partir de suas reflexões" (p. 12, grifos nossos). Partindo do princípio de que as obras de Bakhtin foram escritas num período que antecede o surgimento da pesquisa na internet, então não haveria como ele responder a todas as nossas inquietações dessa pesquisa, ainda assim temos muito a dizer e a pensar a partir de seus escritos. Amorim (2001, p. 108) caminha nesta mesma ideia e diz que "procura na obra de Bakhtin respostas que ele não deu, posto que suas questões não eram nossas", mas reconhece que as contribuições do filósofo demostram pertinência e auxiliam o pesquisador contemporâneo com ideias valiosas.

Além das contribuições bakhtinianas de dialogismo e alteridade, este texto busca inspiração nos pressupostos da etnografia virtual. Ainda são insipientes as pesquisas da área de educação que adotam a internet como campo de investigação e, por isso, abordagens teórico-metodológicas como a etnografia virtual são pouco conhecidas e estudadas na área. De acordo com Gutierrez (2009), os recentes fenômenos da cultura digital que emergem no ciberespaço implicam em novos desafios metodológicos para a pesquisa com internautas e por isto seria necessário hibridizar teorias, métodos e técnicas. Pelos baixos custos de se fazer pesquisa online e pela familiaridade que muitos pesquisadores têm com a rede mundial de computadores, a internet constitui-se como um campo de pesquisa atraente e promissor (HINE, 2005). A etnografia virtual aponta caminhos para pensar a investigação em um novo locus de pesquisa que reconhece e legitima a produção de conhecimentos que vem sendo, mais recentemente, exercida cotidianamente pelos sujeitos nos ambientes virtuais (id., ibid.). Ainda que não exista uma única forma de se apropriar da etnografia virtual, cabe ao 
pesquisador optar pela forma como a pesquisa no ciberespaço será conduzida (ROCHA; MONTARDO, 2005).

Em sua pesquisa de doutorado, Macedo (2012) reflete metodologicamente sobre a investigação com crianças em sites de redes sociais da internet, revelando que há uma grande quantidade de termos para mencionar as pesquisas no ciberespaço, como ciberetnografia, webetnografia, netnografia, etnografia virtual e etnografia online. ${ }^{1}$ Sobre os termos etnografia virtual e netnografia, Amaral (2009) revela que o primeiro tem sido mais usado pelos pesquisadores da área do marketing e da administração, enquanto o segundo tem sido mais empregado nas ciências sociais. Em função da quantidade de termos que emergem com os estudos desenvolvidos na internet, partimos principalmente das contribuições de Christine Hine, que inspira-se na antropologia para pensar a relação com os sujeitos na rede mundial de computadores. Hine (2005) utiliza a nomenclatura "etnografia virtual" para evidenciar que não se trata da mera transposição do método etnográfico para a realização da pesquisa no ciberespaço. A própria distância física entre os sujeitos nas investigações online supõe repensar a abordagem a ser utilizada pelo pesquisador.

Este texto é fruto de pesquisa que vem sendo realizada no Facebook com cerca de 80 jovens internautas que não se reconhecem dentro do modelo hegemônico da heterossexualidade. ${ }^{2}$ Os sujeitos são estudantes das ciências biológicas que cursam a graduação e a pós-graduação em uma universidade pública do Rio de Janeiro. Eles integram um grupo fechado na referida rede social, cujo objetivo é discutir questões relacionadas aos gêneros e às sexualidades, com um enfoque sobre as homossexualidades. Ainda que o foco principal da pesquisa seja discutir a heteronormatividade, o objetivo deste texto é refletir teórica e metodologicamente os caminhos trilhados no estudo de campo.

\section{COAUTORIA, PSEUDÔNIMOS E PARTICIPAÇÃO NA PESQUISA: “TUDO O QUE VOCE DISSER VIRA PESQUISA"}

Reconhecer a coautoria de todos os envolvidos na investigação implica também em refletir sobre a nomeação dos sujeitos na escrita do texto. Concordo com Kramer (2002, p. 47) que, na sua pesquisa com crianças, aponta:

De antemão recusamos alternativas tais como usar números, mencionar as crianças pelas iniciais ou as primeiras letras do seu nome, pois isso negava a sua condição de sujeitos, desconsiderava a

\footnotetext{
${ }^{1}$ Fazemos uso do termo online para nos referir à conversa mediada pelo computador. Em contrapartida, o termo offline diz respeito às interações face-a-face, presenciais.

${ }^{2}$ Dilton Junior, um dos autores deste artigo, integra esse grupo de jovens no Facebook.
} 
sua identidade, simplesmente apagava quem era e as relegava a um anonimato incoerente com o referencial teórico que orientava a pesquisa.

Em coerência com a abordagem teórico-metodológica da etnografia virtual, que sugere a participação ativa e colaborativa entre pesquisador e sujeitos, assumimos o caráter dialógico e de alteridade na relação com os nossos tantos outros, optando pelo uso de pseudônimos escolhidos pelos próprios participantes da pesquisa. Essa opção revela melhor quem são e o que pensam os sujeitos da pesquisa, pois a escolha de um nome fictício traz a possibilidade de conhecermos suas aspirações e desejos no mundo do entretenimento e da cultura, ao mesmo tempo que inúmeras histórias do contexto familiar são reveladas. Personagens de seriados e filmes norte-americanos e europeus, bem como apelidos criados pela família e amigos estão dentre os pseudônimos mais escolhidos pelos sujeitos, conforme apresentamos a seguir. Conversando individualmente no chat do Facebook, cada integrante do grupo informou o motivo da escolha de seu pseudônimo: ${ }^{3}$

Oliver: pode ser qualquer coisa mesmo? pq eu gosto de alguns nomes pessoais aleatórios.

Dilton: claro, algo que voce se identifique. Tudo o que voces postam viram material de campo (;)

Oliver: aaaaaaaah é mesmo.

Dilton: entao nada melhor do que voce se identificar depois na escrita dos textos. Eu antigamente usava siglas. Achava meio impessoal.

Oliver: então eu escolho Oliver.

Dilton: Oliver? por quê? (curiosoooo) hehe.

Oliver: personagem de um seriado/novela que eu gosto. Ele é gay.

Dilton: eh o cozinheiro da tv? ou viajei na maionese? Ops... chef de cozinha hehe.

Oliver: Cheeeeeeeeeef não, ele é auxiliar tipo um garçom. É alemã, vi agora. Sempre achei ele fofíssimo, o ator interpretava muito bem.

Dilton: ih, entao nao estamos falando da mesma coisa. Estava me referindo ao outro.

Oliver Entao.

Dilton: GOOGLE me ajude: Série de culinária em que o chef britânico Jamie Oliver prepara pratos deliciosos para o seu dia a dia.

Oliver: nãaaaaaaaao rsrs

Dilton: heheheh que coincidência! pelo menos os dois trabalham com comida! hehehe

Oliver: Hahha é mesmo. ${ }^{4}$

Pesquisar dentro das dinâmicas sociais da internet permite conhecer a forma como os sujeitos interagem e se apropriam das informações (HINE, 2011). Sites de busca como o Google (www.google.com) e vídeos do YouTube (www.youtube.com) são facilmente compartilhados pelos

\footnotetext{
${ }^{3}$ Ficaria muito extenso apresentar todas as conversas online acerca dos pseudônimos escolhidos pelos sujeitos da pesquisa. Em função disso, selecionamos apenas algumas dessas conversas.

${ }^{4} \mathrm{O}$ vídeo compartilhado por Oliver na conversa está disponível no Youtube no endereço: <http://www.youtube.com/watch?v=tBtmOwhytnw>; você também poderá acessá-lo usando dispositivo móvel pelo QR-Code ao lado.
} 
sujeitos no Facebook, tornando rica a possibilidade de troca de arquivos e informações. Envolvendo explicações da Wikipedia (www.wikipedia.org) e o compartilhamento de uma imagem da internet, a conversa a seguir tanto revela a opção pela escolha do pseudônimo, como não deixa dúvidas sobre as possibilidades de ensinar-aprender com o outro a partir da conversa mediada pelo computador:

Dilton: Só preciso de um pseudônimo para você ser identificado na pesquisa

\section{Ragon: Ragon}

Dilton: Ragon é apelido (na universidade)?

Ragon: auhsuahs não é apelido não

Dilton: surgiu de onde o nome Ragon?

Ragon: auhsuha. Então...

Dilton: tudo o que você disser vira pesquisa (;)

Ragon: esse nome é parecido ou é o nome (já não me lembro ao certo) de uma espícula de porífera que aprendi na aula, ai o nome ficou na minha cabeça pq achei um nome com muita presença. Forte. Entende? Ai desde então não esqueço dele

Dilton: ah, que máximo! já está anotado! vou procurar no google o que é... espícula de porífera? ... porífera eu ouvi falar no ensino médio (e com a minha memória fraca, nem lembro mais)

Ragon: aushaush

Dilton: não prefere me dizer o que é? resumidamente? faciliaria a compreensão para os leigos (porque pela definição da wikipedia, acho que ferrou de vez! rs)

Ragon: espicula de porífera são aqueles espinhos que ficam dentro da esponja

Dilton: ahhh, maravilha!

Ragon: ai pode ser de calcário ou sílica ${ }^{5}$

Dilton: sua explicação é melhor do que a que eu encontrei:

O "esqueleto" das esponjas pode ser formado por espículas calcárias ou siliciosas, por fibras de espongina ou por placas calcárias. (Wikipedia) vleu!

Ragon: aushauhsuahs verdade

Dilton: ahuauhahuahuau

Ragon: essas espículas que dão sustentação para as esponjas e a rigidez, mas não são esqueletos rsrs

Dilton: ah, isso eu entendi entao. Deixa a biologia com voces, se eu precisar eu pergunto. É muito nome, nao sei como voces dão conta. E fico feliz que deem conta, alguem precisa entender tudo isso

Ragon: aushauhsuah tá certo

Dilton: rs.

De acordo com Bakhtin (2011, p. 394), quando nos abrimos para o outro, entramos no “campo das descobertas, das revelações, das tomadas de conhecimento, das comunicações", e é

\footnotetext{
5 A imagem compartilhada por Ragon na conversa está disponível no endereço: <http://www.sobiologia.com.br/figuras/Reinos2poriferos.jpg>; você também poderá acessá-lo usando dispositivo móvel pelo QR-Code ao lado.
} 
justamente nessa abertura proporcionada pela relação de cumplicidade estabelecida na conversa online acima que pesquisador e sujeitos tornam-se protagonistas e coautores ativos do estudo, inspirados pela vontade de estreitar os vínculos e pela curiosidade que cada momento de interação é capaz de proporcionar no contato com o outro. Ragon é mais do que um mero pseudônimo, mas remete à uma identificação "com muita presença. Forte. Entende? Ai desde então não esqueço dele". Jovem graduando das ciências biológicas, Ragon forneceu elementos necessários para incentivar e enriquecer melhor o entendimento sobre o mundo das "poríferas". Sobre isso, remetemo-nos aos dizeres de Geraldi (2013, p. 15), ao mencionar que "se no mundo da vida não saímos de um diálogo sem com ele nos enriquecermos, também nos processos educativos professor e aluno saem diferentes, porque nessa relação ambos aprendem”. Acrescentamos também o quanto é possível aprender-ensinar no caminhar de uma pesquisa que prima não pela mera observação e coleta de dados, mas pelo encontro com o outro, pela produção de discursos que sejam capazes de contribuir com novas reflexões. Na ótica bakhtiniana, o encontro com o outro é um acontecimento: livre, único e irrepetível.

Atribuindo importância às indagações, a jovem que optou pelo pseudônimo Mafalda revela o porquê de sua escolha:

Dilton: escolha um nome que voce achar legal, que voce consiga se identificar bastante

Mafalda:.. pode valer Mafalda? sempre questionando...

Dilton: claro que pode. E posso perguntar... por que Mafalda?

Mafalda: porque é uma das personagens mais questionadoras que a gente tem.. que enxerga de uma maneira diferente as coisas a sua volta

Dilton: e voce se acha questionadora, que nem a Mafalda?

Mafalda: acho que ja fui mais (o que talvez seja um dos grandes problemas de "crescer"). Era meu apelido entre os professores da escola, pelo exato motivo de ser questionadora

Dilton: e isso foi ruim na escola?

Mafalda: isso foi sensacional

Dilton: por quê? Pode falar a vontade se quiser. eu vou adorar ouvir (ou melhor, ler) rs

Mafalda: hahahaha primeiro, porque me fez me sentir mais a vontade pra realmente questionar aulas, conhecimento passado e outras questões. Depois, eu parei pra reparar no meu próprio comportamento. e reparei que eu realmente reparava muito nas coisas e questionava motivos, métodos, fazia comparações .. me ajudou a perceber que eu sou

Dilton: e voce sentia abertura dos professores para dialogar com eles e com a turma?

Mafalda: alguns sim, alguns não .. é sempre assim... mas, no geral, sim

Dilton: ah, que maravilha. e questione sempre. Nada como alguem para perguntar e fazer o povo pensar pontos que antes nao foram pensados. Pensar abala as estruturas rigidas e que supostamente sao inflexiveis!

Mafalda: porque nao existe uma verdade, mas sim varias verdades diferentes..

Dilton: é verdade rs... a verdade, a meu ver, é sempre momentânea. E os diversos olhares ajudam a relevar verdades que passam despercebidas... 
O pensamento do pesquisador não pode ser soberano, uma vez que, na perspectiva dialógica e alteritária bakhtiniana, "a verdade não se encontra no interior de uma única pessoa, mas está na interação dialógica entre pessoas que a procuram coletivamente” (JOBIM E SOUZA, 2007, p. 92). É pela importância em aprender-ensinar com os sujeitos, e não sobre eles, que privilegiamos a formulação de perguntas na tentativa de conhecer melhor outros pontos de vista, ao mesmo tempo em que a própria comunicação dialógica instaurada no estudo de campo permite que os internautas conheçam melhor o pesquisador. Concordamos com Hine (2011), quando revela que buscar inspiração nas pesquisas de cunho etnográfico possibilita compreender as práticas culturais dos sujeitos sem assumir de antemão ideias pré-concebidas, mas abrir novas possibilidades para o território das reflexões teóricas.

Adotar a estratégia de tornar os sujeitos autores de seus próprios pseudônimos se tornou uma atividade instigante para que eles se deixassem conhecer na pesquisa. Larrosa (2002, p. 21) afirma ainda que "quando fazemos coisas com as palavras, do que se trata é de como damos sentido ao que somos e ao que nos acontece, de como correlacionamos as palavras e as coisas, de como nomeamos o que vemos ou o que sentimos e de como vemos ou sentimos o que nomeamos". Além da opção pela forma como os sujeitos se intitularam neste estudo, de quais outras formas podemos usar as palavras na pesquisa em educação para conhecer cada vez mais e melhor os sujeitos? Se é na linguagem que nós conhecemos o outro e nos deixamos conhecer, quais os cuidados necessários com a utilização das palavras na pesquisa com sujeitos geograficamente dispersos? A abordagem da etnografia virtual privilegia as relações online, mas não desconsidera as possibilidades de pesquisar e interagir face-a-face com os sujeitos da investigação, conforme discutimos a seguir.

\section{A RELAÇÃO COM O OUTRO NA ESCOLHA DOS PROCEDIMENTOS METODOLÓGICOS: "GOSTO DE LIDAR COM AS PESSOAS PESSOALMENTE"}

É cada vez mais difícil conceber a internet como um "mundo virtual paralelo" quando nossas atividades diárias são intensamente mediadas pelas tecnologias digitais em rede (SANTAELLA, 2010). Um encontro entre amigos pode ser agendado num site de rede social, se concretizar na ida de todos à praia e novamente voltar à internet para a continuação do bate-papo e fortalecimento da amizade, ao mesmo tempo em que um internauta pode encontrar seu vizinho no mercado e, posteriormente a isso, continuar trocando ideias com ele por e-mail e/ou Facebook. É em função disso que novos desafios metodológicos são lançados para as pesquisas que se debruçam em investigar as redes sociais que estão constituindo-se na internet. 
A internet encoraja que os pesquisadores não apenas foquem na investigação de um grupo específico de internautas, mas explorem também formas mais dinâmicas de estabelecer o contato com sujeitos em mais de um campo empírico (HINE, 2011). Além da escolha de um campo de pesquisa na internet, Hine (2009) apresenta inúmeras possibilidades metodológicas na etnografia virtual, como a realização de entrevistas presenciais, análise de fontes documentais impressas, interação com os sujeitos pelo e-mail, dentre outras. Hine (2008) prevê também a possibilidade de entrar em contato individualmente com os sujeitos da pesquisa para a realização de entrevistas presenciais (face-a-face).

No caso específico da presente investigação, alguns sujeitos do Facebook revelaram o interesse em conversar pessoalmente e intercambiar outras ideias, conforme fica claro na conversa com Ragon (1) em agosto de 2013 e, posteriormente, com Sofia Madeira (2) em outubro do mesmo ano:

Ragon: [...] se não tiver problema gostaria de poder marcar um horário ou algo do tipo pq gosto de lidar com as pessoas pessoalmente, e como seu trabalho é sobre um tema atual e "polêmico" acho q uma conversa mesmo q informal seja melhor que pelo face. Claro, se vc concordar

Dilton: Claro, Ragon! Mais do que justo. Conversar pessoalmente é muito legal também. Você estuda na [Universidade $\mathrm{X}^{6}$ ] atualmente?

Ragon: sim e tb faço estágio, então qq dia e qq hora estarei lá

$[\ldots]$

Ragon: Sim, claro e se marcar com alguns membros do grupo acho q a conversa pode ser mais produtiva

Dilton: [...] Posso deixar você marcar com quem você se identifica mais no grupo? De repente você e mais 1 ou 2. [...]

Ragon: Se vc acha melhor até pq o trabalho é seu rsrs (é pq não sei como vc esta fazendo, se tem tempo e tals) e tb participei do grupo de diversidade e gênero da bio e as conversas eram bem produtivas qndo eram um grupo de até 6 pessoas. Sem problema. Se quiser até individual tb pode ser.

Dilton: Ragon, os sujeitos, para as pesquisas em educação que vimos desenvolvendo, sao tudo! Sem voces, nossas pesquisas nao teriam sentido. Entao pode deixar que marco em breve com voce (e quem mais voce quiser convidar). Terei que montar um pequeno roteiro (com algumas perguntinhas iniciais). Mas a conversa pode seguir o rumo que voces quiserem.

Ragon: |Uahsaus sim sem problema. Adoro responder perguntas. Então sem problema

Dilton: Voce nao faz meramente responder, voce vai me ajudar a pensar $(;)$

Ragon: tb gosto rsrs.

Dilton: rsrs é um tema muito complexo, e que precisa ser trabalhado na escola. E fora dela, obviamente.

Ragon: principalmente hj em dia.

\footnotetext{
${ }^{6}$ Substituímos a sigla da universidade na qual o jovem estuda por "Universidade X".
} 
Dilton: com certeza. Vou adorar conversar com voces então. Vamos nos falando e voce pode ir vendo com mais 1 ou 2 amigos do grupo. Vou indo la. Vamos nos falando e obrigado, Ragon! vai ser legal!

2

Sofia Madeira: Quando quiser 'entrevistar' pra pesquisa, só falar!

Dilton: Claro. na verdade eu tenho focado, pelo menos neste momento, nas nossas conversas no facebook mesmo. é muita escrita p pouco pesquisador rsrs Eu até andei conversando com o JR Wilde, e queria marcar com alguns membros do grupo lá [na faculdade de vocês]. Para conversar.

Sofia Madeira: ahamm só marcar! Tem muita gente que eu nem conheço também. Seria muito bom saber quem são... terceiro periodo também, hahahahahaha.

Dilton: pode ser uma oportunidade mesmo p marcar e cada um se conhecer...

A pesquisa em ciências humanas que investiga dentro da ótica dialógica eu-outro tem o próprio ato da escrita como constituinte do processo de pesquisa. Tal ato compreende a responsabilidade do autor pelas reflexões tecidas em um determinado momento, ou seja, "a assinatura do ato de pensar" (JOBIM E SOUZA; ALBUQUERQUE, 2012, p. 117). Considerando a coautoria dada aos sujeitos durante a investigação, a assinatura do pesquisador faz com que o texto seja concebido também como acontecimento, uma vez que não permite previsibilidade ou controle por parte do autor (AMORIM, 2002). É na relação com os jovens que vimos tecendo reflexões sobre o que foi discutido no Facebook. Embora compreendamos que o trabalho seja assinado pelo pesquisador ("se vc acha melhor até pq o trabalho é seu rsrs"), consideramos prudente ressaltar para Ragon que "Sem vocês [sujeitos], nossas pesquisas nao teriam sentido". Esta pesquisa vem sendo, portanto, desenvolvida na relação com os jovens no Facebook, considerando a importância da comunicação dialógica. Concordamos com Geraldi (2013, p. 15), para quem

O diálogo é uma maneira criativa e produtiva do eu se aproximar com suas palavras às palavras do outro, construindo uma compreensão que, por não ser de mero reconhecimento dos signos usados, é sempre uma proposta, uma oferta, uma resposta aberta a negociações e a novas construções.

A partir do diálogo com Ragon e Sofia Madeira, dentre outros participantes da pesquisa, consideramos a proposta dos jovens de marcar uma entrevista face-a-face bastante favorável. Seria uma oportunidade também para que os próprios sujeitos se conheçam melhor, como o caso de Sofia Madeira, que cursa o terceiro período das ciências biológicas: "só marcar! Tem muita gente que eu nem conheço também. Seria muito bom saber quem são... terceiro periodo também". Vale ressaltar também o interesse e o envolvimento de Ragon pelas questões referentes aos procedimentos metodológicos da pesquisa: "não sei como vc esta fazendo, se tem tempo e tals". Neste sentido, a partir do uso de entrevistas semiestruturadas, consideramos importante a conversa presencial como mais uma possibilidade de aprender-ensinar com o outro. Conforme foi esclarecido a Ragon: "voce nao faz meramente responder [perguntas], voce vai me ajudar a pensar (i)'. 
A partir das contribuições da etnografia virtual, faz-se interessante buscar outras formas de estabelecer o contato com os grupos sociais, não se restringindo única e exclusivamente aos diferentes sites da internet. Dessa forma, quais espaços offline poderiam ser adotados pelo pesquisador para estabelecer o contato com os sujeitos no estudo de campo? Como estabelecer critérios para selecionar esses espaços? Segundo Hine (2011 p. 579, grifos nossos), "ao escolher espaços para prosseguir com o estudo online para o offline, nós seremos limitados geograficamente da mesma forma que seremos limitados pela possibilidade de aprofundar o estudo em apenas alguns espaços selecionados". 7 Neste sentido, é necessário o diálogo aberto a negociações para considerar a possibilidade do encontro presencial com o outro.

\title{
QUANTIDADE SIGNIFICATIVA DE POSTAGENS: "FICA AÍ AVALIANDO A GENTE E NEM CONSEGUE MAIS ACOMPANHAR"
}

\begin{abstract}
A grande quantidade de conteúdos produzidos pelos usuários e hoje disponíveis na internet, e a possibilidade de pesquisar por comentários relevantes e passar despercebido nos lugares em que os conteúdos são produzidos, oferece uma nova possibilidade para os pesquisadores que estudam as mídias estejam onde as pessoas estão e capturem algumas das formas como elas se relacionam com as mídias. ${ }^{8}$ (HINE, 2011, p. 570).
\end{abstract}

Conforme anteriormente mencionado no início deste texto, há formas distintas de pesquisar no ciberespaço. Na citação, Christine Hine aponta a possibilidade de pesquisar sem ser percebido pelos sujeitos, meramente observando situações cotidianas na internet. A partir da abordagem teórico-metodológica da etnografia virtual e das contribuições de Mikhail Bakhtin, a nossa opção é pela participação colaborativa nas dinâmicas sociais de um grupo de jovens no Facebook. O que pretendemos destacar agora, a partir das palavras de Hine (2011) acima, refere-se à quantidade exponencial de informação produzida e compartilhada pelos internautas. Apenas para ilustrar o número de pessoas que vêm participando dos processos comunicacionais nos sites de redes sociais, em 2011 havia 800 milhões de usuários no mundo cadastrados no Facebook e cerca de 200 milhões de pessoas participando do Twitter (RECUERO, 2012). E o número de usuários de redes sociais continua crescendo. Dito isso, muitos internautas utilizam intensamente os recursos comunicacionais disponíveis na rede mundial de computadores, não deixando dúvidas da

\footnotetext{
${ }^{7}$ Tradução de: "in choosing places to move the study offline we will, of course, be limited by geography as much as by the limitations of being able to explore in depth only in a few selected places". (HINE, 2011, p. 579).

${ }^{8}$ Tradução de: "The sheer quantity of user-generated content now available on the internet, and the possibility of searching for relevant remarks and unobtrusively lurking in the places where they are generated, offers a renewed possibility for media studies researchers to 'hang out' where people are and capture some of the ways that they engage with media". (HINE, 2011, p. 570).
} 
quantidade inesgotável de informação produzida e compartilhada na Web. É em função disso que, na pesquisa em andamento de doutorado, a escolha por um grupo específico no Facebook, de aproximadamente 80 jovens, torna viável que o pesquisador converse com todos, individual e coletivamente, ao mesmo tempo em que permite uma análise cuidadosa das informações produzidas no diálogo em rede.

Quando a conversa online apresenta a participação de vários internautas, é exigido do pesquisador maior atenção e esforço no sentido de interagir com o grupo e contribuir com a discussão. Nem sempre o pesquisador obtêm êxito na tarefa de participar ativamente de conversas que apresentavam centenas de comentários, conforme Dilton apontou para Thayane, Justgia e JR Wilde em setembro de 2013, no trecho abaixo:

Dilton: gente, vocês são muito rápidos nas ideias... eu nem li a noticia que a Justgia postou e vocês já estou comentando hahahahahah

Justgia: Dilton fica aí avaliando a gente e nem consegue mais acompanhar

Dilton: que nada!!! hahaah sou lerdo mesmo. avaliando?! credo. rssrsrs eu salvo as informações depois... dias depois.

Mesmo dialogando com apenas três jovens, Thayane, Justgia e JR Wilde, a participação se tornou desafiante pela rapidez e dinamicidade com a qual os comentários dos sujeitos foram produzidos e postados no grupo. Na conversa em questão, inúmeros links com vídeos, notícias e imagens foram também postados, propiciando que uma quantidade de informação ainda maior estivesse veiculada aos comentários dos sujeitos. Diante do exposto, o que observar nas dinâmicas do grupo? Quais seriam os critérios para salvar as informações produzidas com os sujeitos? Como armazenar essas informações? Não há respostas corretas e definitivas às referidas perguntas, e tudo dependerá dos objetivos a que se propõe o pesquisador.

Na pesquisa, a escolha por um grupo de jovens no Facebook favoreceu que as dinâmicas de interação pudessem ser melhor observadas e analisadas à luz das questões norteadoras da investigação. A opção por permanecer focado num único grupo de jovens aponta para o interesse no fortalecimento dos vínculos com cada um de seus integrantes. Ainda que o foco esteja em apenas um grupo no Facebook, a quantidade de informação produzida e postada pelos usuários não é pequena. Em diversas ocasiões, centenas de comentários são postados diariamente.

Apesar da participação no grupo ser maior à noite, os sites de redes sociais da internet podem ser acessados 24 horas por dia, todos os dias da semana. Isso significa que há certos desafios e limites na pesquisa online. Se podemos acessar a internet de praticamente qualquer lugar do mundo e a qualquer horário do dia, quando começa e quando termina a pesquisa de campo? Indo nessa mesma direção e refletindo sobre a quantidade de dados produzidos na pesquisa online, 
Macedo (2012, p. 9) propõe duas perguntas instigantes: "como medir a intensidade do mergulho em campo quando ele está a um clique de distância? Mais: como mergulhar sem se afogar?”. Essas perguntas são fundamentais para o pesquisador que pretende investigar grupos de sujeitos na internet; grupos que, devido às diferentes rotinas diárias, produzem e postam informações durante os mais variados horários e dias da semana.

As palavras de Nilda Alves (2008) a seguir imprimem à pesquisa a postura que defendemos. A autora considera imprescindível compreender que a metodologia deve ser pensada e gradualmente construída com o objeto:

Em relação ao método, tenho que começar por admitir que estou sempre cheia de dúvidas e sobre ele tenho muito que aprender. Mas, como sempre digo aos meus orientandos: "É preciso fazer, para saber". O poeta Antônio Machado é lembrado nessas ocasiões: Caminhante não há caminho / Se faz caminho a andar... (p. 16, grifos da autora).

É dentro deste contexto exposto por Alves (2008) que vimos aprendendo a pesquisar na internet. Longe de saber tudo e de desconsiderar outras formas de pesquisa online, as contribuições do filósofo Mikhail Bakhtin e da pesquisadora Christine Hine vêm se tornando imprescindíveis no caminhar investigativo no ciberespaço. Somando-se a eles, o diálogo com os sujeitos do estudo de campo fornecem questões igualmente importantes ao longo da caminhada que é a pesquisa na internet.

\section{CONCLUSÃO}

a escrita não é nunca o trabalho de fechamento de uma pesquisa, mas o território onde suas questões ganham vida. É no rascunhar, no ler, no rever, no apagar, no refazer, no ressignificar da escrita que a pesquisa se estrutura e as relações de alteridade se formalizam (PEREIRA, 2012, p. 82).

A quantidade expressiva de dados produzidos com os jovens no Facebook tornou a escrita deste trabalho desafiante e, ao mesmo tempo, instigante, relevando a potência do diálogo em rede. Pesquisar na internet com o outro é conviver num espaço múltiplo e plural, ativamente habitado por aqueles que apreciam e desejam estar juntos, fortalecendo os vínculos sociais e afetivos.

Sobre o eu e o outro, Geraldi (2013, p. 18) comenta que "ambos [somos] incompletos, só temos uma forma de relação que possa preencher o vazio: a aproximação dialógica é a forma de encontrar completudes provisórias". Isso significa compreender que nos completamos provisoriamente na relação com o outro, enquanto que o outro é igualmente afetado pela incompletude provisória que damos a ele. É na relação com as diferenças que as completudes provisórias se manifestam, segundo os princípios bakhtinianos. Se é o outro que nos completa e nos 
dá o acabamento, o vazio de cada um é preenchido pelas histórias do outro; sem essas histórias, as nossas tampouco fariam sentido. Os encontros na internet produzem múltiplos sentidos, com cada conversa online narrada pelo outro constituindo-se pelo entrelaçamento de diferentes pontos de vistas. Dessa forma, a etnografia virtual se torna importante nas pesquisas acadêmicas como uma forma de se conhecer a relação das pessoas com a internet (HINE, 2008).

Não necessariamente pensamos igual, mas é na diferença, na relação de alteridade construída, que cada ponto de vista amplia o entendimento sobre as questões apresentadas. Ao assumir o dialogismo e a alteridade como princípios éticos na investigação, o encontro com outros internautas torna-se um momento único, com cada conversa online sendo reconhecida pelo seu compromisso de buscar cada vez melhor os sentidos construídos entre pesquisador e sujeitos. Esse foi o motivo que nos levou a escolher a referida abordagem como procedimento, tendo em vista sua propriedade na pesquisa que se debruça sobre os fenômenos comunicacionais entre sujeitos geograficamente dispersos, com a internet se constituindo como uma interface que garante o lugar de encontro com o outro. 


\section{REFERÊNCIAS}

ALVES, Nilda. Decifrando o pergaminho - os cotidianos das escolas nas lógicas das redes cotidianas. In: OLIVEIRA, Inês B.; ALVES, Nilda. (Orgs.). Pesquisa nos/dos/com os cotidianos das escolas: sobre redes de saberes. Petrópolis: DP et Alii, 2008. p. 15-38.

AMARAL, Adriana. Autonetnografia e inserção online: o papel do pesquisador-insider nas práticas comunicacionais das subculturas da Web. Revista Fronteiras - estudos midiáticos. v. 11, n. 1, p. 14-24, jan./abr. 2009.

AMORIM, Marília. O pesquisador e seu outro: Bakhtin nas ciências humanas. São Paulo: Musa Editora, 2001.

. Vozes e silêncio no texto de pesquisa em ciências humanas. Cadernos de Pesquisa, n. 116, p. 7-19, jul. 2002.

BAKHTIN, Mikhail. Estética da criação verbal. Trad.: Paulo Bezerra. 6. ed. São Paulo: Martins Fontes, 2011.

Problemas da poética de Dostoiévski. Trad.: Paulo Bezerra. 4. ed. Rio de Janeiro: Forense Universitária, 2008.

GERALDI, João W. Bakhtin tudo ou nada diz aos educadores: os educadores podem dizer muito com Bakhtin. In: FREITAS, Maria T. A. (Org.). Educação, arte e vida em Bakhtin. Belo Horizonte: Autêntica Editora, 2013. p. 11-28.

GUTIERREZ, Suzana S. A Etnografia virtual na pesquisa de abordagem dialética em redes sociais on-line. In: ANPED. Anais da 32. Reunião... Caxambu: Espaço Livre, 2009. 16p.

HINE, Christine. Internet research and the sociology of cyber-social-scientific knowledge. The information society: an international journal, Reino Unido, 21:4, p. 239-248, 2005.

. Virtual ethnography: modes, varieties, affordances. In: FIELDING, Nigel; LEE, Raymond M.; BLANK, Grant. (Orgs.). The SAGE handbook of online research methods. Los Angeles: Sage, 2008. p. 257-270.

. How can qualitative internet researchers define the boundaries of their projects? In: MARKHAM, Annette N.; BAYM, Nancy. (Orgs.). Internet inquiry. Conversations about method. Los Angeles: Sage, 2009. p. 1-20.

Towards ethnography of television on the internet: a mobile strategy for exploring mundane interpretive activities. Media, Culture \& Society, Reino Unido, 33(4), p. 567- 582, 2011.

JOBIM E SOUZA, Solange. Dialogismo e alteridade na utilização da imagem técnica em pesquisa acadêmica: questões éticas e metodológicas. In: FREITAS, Maria T. A.; JOBIM E SOUZA, Solange; KRAMER, Sonia. (Orgs.). Ciências humanas e pesquisa: leituras de Mikhail Bakhtin. São Paulo: Cortez, 2007. p. 77-94.

; ALBUQUERQUE, Elaine Deccache Porto. A pesquisa em ciências humanas: uma leitura bakhtiniana. Bakhtiniana, São Paulo, v. 7, n. 2, p. 109-122, jul./dez. 2012.

KRAMER, Sonia. Autoria e autorização: questões éticas na pesquisa com crianças. Cadernos de Pesquisa, n. 116, p. 41-59, jul. 2002.

LARROSA, Jorge. Notas sobre a experiência e o saber de experiência. Revista Brasileira de Educação, n. 19, p. 20-28, jan./fev./mar./abr. 2002.

MACEDO, Nélia M. R. Crianças e redes sociais: uma proposta de pesquisa online. ANPED. Anais da 35 Reunião... Porto de Galinhas. Educação, cultura, pesquisa e projetos de desenvolvimento: o Brasil do século XXI, 2012, 17p.

PEREIRA, Rita Marisa R. Pesquisa com crianças. In: PEREIRA, Rita M. Ribes; MACEDO, Nélia M. Rezende. (Orgs.). Infância em pesquisa. Rio de Janeiro: Nau, 2012. p. 59-86.

RECUERO, Raquel. A conversação em rede: comunicação mediada pelo computador e redes sociais na internet. Porto Alegre: Sulina, 2012.

ROCHA, Paula Jung; MONTARDO, Sandra Portella. Netnografia: incursões metodológicas na cibercultura. Revista Ecompós, Brasília, vol. 4, dez. 2005.

SANTAELLA, Lucia. A ecologia pluralista da comunicação: conectividade, mobilidade, ubiquidade. São Paulo: Paulus, 2010. 


\section{RESUMO}

Este artigo tem como objetivo promover reflexões teórico-metodológicas sobre caminhos possíveis na pesquisa com jovens internautas. Para isso, apropriamo-nos da abordagem dialógica de Mikhail Bakhtin, segundo a qual pesquisador e pesquisados são concebidos como coautores em um processo de produção de conhecimento que constrói-se gradualmente com o outro. Além disso, a partir das contribuições de Christine Hine, buscamos inspiração na etnografia virtual para compreender os processos comunicacionais que emergem na rede mundial de computadores. Dessa forma, considerando a internet como o lugar de encontro com o outro, concluímos que a relação com os sujeitos é imprescindível para as reflexões de pesquisa nos ambientes virtuais.

Palavras-chave: Etnografia virtual. Alteridade. Dialogismo.

\section{“EVERYTHING YOU SAY BECOMES PART OF THE RESEARCH”: TRACING THEORETICAL-METHODOLOGICAL PATHS IN A RESEARCH WITH INTERNET USERS}

\section{ABSTRACT}

This article has the objective to promote theoretical and methodological reflections on possible paths in a research with young Internet users. Henceforth, we appropriate ourselves with the dialogic approach of Mikhail Bakhtin, whereby researcher and researched are conceived as co-authors in a process of production of knowledge that builds gradually with the other. In addition, from the contributions of Christine Hine, we seek inspiration in virtual ethnography to understand the communicational processes that emerge on the World Wide Web. Thus, considering the Internet as a place of encounter with the other, we conclude that the relationship with the subjects is essential to the research reflections in the virtual environments.

Keywords: Virtual ethnography. Otherness. Dialogism.

Submetido em Dez. 2015

Aprovado em Maio 2016 